\title{
The effect of flabelliferins of palmyrah fruit pulp on intestinal glucose uptake in mice
}

\author{
r. Uluwaduge ${ }^{1 *}$, M.I.Thabrew ${ }^{1}$ and E.R.Jansz ${ }^{2}$ \\ Department of Biochemistry \& Clinical Chemistry, Faculty of Medicine, University of Kelaniya, Thallagolla Rd., Ragama. \\ ? Department of Biochemistry, Faculty of Medical Sciences, University of Sri Jayewardenepura, Nugegoda.
}

Revised : 30 June 2005; Accepted: 23 August 2005

\begin{abstract}
Palmyrah (Bourssus flabellifer L.) is a tree found growing in arid climates. It has an edible fruit pulp. Previous work had shown that Instituce of Cancer Research (ICR) mice fed with 10\% fruit pulp in standard feed showed reduced weight gain due to bitter steroidal saponins termed flabelliferin-II. The effect of this pulp and flabelliferin II on glucose uprake was studied. At a dose of $10 \mathrm{mg} /$ mouse, mixed flabelliferins (with $2.5 \mathrm{mg}$ flabelliferin II) reduced blood glucose afrer glucose challenge $(p<0.001)$, increased faccal glucose $(p<0.001)$ and intestinal glucose $(p<0.001)$, but not faccal glucose $(p=0.62)$. The latter is probably due to the removal of flabelliferin triglycoside which is antimicrobial. The antimicrobial component and wo otber flabelliferins did not show the above effect. As the pulp is non-toxic it may find application as a functional food.
\end{abstract}

Keywords: Flabelliferins, glucose uptake, ICR mice, palmyrah fruit pulp.

\section{INTRODUCTION}

Flabelliferins, a family of steroidal saponins in the fruit pulp of palmyrah (Borassus flabellifer L., Family: Arecaceae) were first highlighted in 1994. Of the flabelliferins isolated so far from the crude flabelliferin mixture, a tetraglycoside flabelliferin-II (F-II), with two rhamnosyl moieties and two glucosyl moieties, is responsible for the bitterness in palmyrah fruit pulp.' F-II has also been shown to inhibit A'TPase of ghost red blood cells. ${ }^{2}$ Debittering of Palmyrah Fruit Pulp (PFP) by the enzyme naringinase causes the loss of F-II (and bitterness) and another flabelliferin, flabelliferin $B(F B)$, a branched flabelliferin triglycoside. ${ }^{3}$ Flabelliferin $B$ was shown to have potent anti-yeast and anti-bacterial activity. ${ }^{+}$It had been observed that PFP caused weight loss in Institute of Cancer Research mice (ICR) despite there being no change in isocaloric feed intake. Feeding of non-bitter PFP (no F-II) did not result in such weight loss thus indirectly implicating F-II as the causative agent for the observed weight loss. Flabelliferins are naturally associated with a uv-active binder ${ }^{6}$ which could have an effect on the extent of their activity.

The objectives of this study were to determine: (i) whether PFP induced weight loss 5,6 were reproducible, (ii) the cause for the weight loss, (iii) whether separation of the uv-active binder would affect bioactivity (iv) and whether therapeutic applications would be feasible.

\section{METHODS AND MATERIALS}

\section{Biological materials}

Experimental animals: Inbred, homogeneous ICR mice ( 4 wk old, $20 \pm 5 \mathrm{~g}$ body weight, weanling males for weight gain studies, and 6 wk old, $35 \pm 5$ g body weight males for other studies) were purchased from the Medical Research Institute, and the experiments were conducted at the animal house, University of Sri Jayewardenepura. The mice were maintained in a temperature-controlled room (30 ${ }^{\circ} \mathrm{C}$ ) under $12 \mathrm{~h}$ light/dark cycle (dark phase 6 p.m to 6 a.m). They were fed with the rat and mouse breeding feed recommended by the World Health Organization (WHO) ${ }^{7}$ or $10 \%$ PFP containing pellet feed and water ad libitum. Feed intake and weight gain were determined by methods previously described. ${ }^{3.5}$

Plant materials: Fruits of palmyrah were collected from Kalpitiya in the North-West of Sri Lanka. The fruit pulp was extracted from its fibrous matrix by extracting manually with a spoon, using water in the ratio of $2: 1 .^{+}$

Extraction of flabelliferin mixture from PFP: The flabelliferin mixture was extracted using methanol followed by de-carotenising with petroleum ether (60-80 $\left.{ }^{\circ} \mathrm{C}\right) .{ }^{1}$ The sugar was separated from extracts using a dry cellulose column. ${ }^{1}$ 
Separation of flabelliferins: Separation of flabelliferins was conducted by using a chromatotron ${ }^{8}$ (Harrison, California, USA). When necessary, further purification was carried out using preparative thin layer chromatography $(300 \mathrm{~mm}$ silica gel $\mathrm{G} 60$ using butanol: ethanol; ammonium hydroxide, specific gravity $0.88=$ 7:3:4). Spraying with anisaldehyde reagent was necessary to monitor fractions and test them for purity. ${ }^{1}$ All flabelliferins contain a uv-active binder. ${ }^{6}$ This was separated using a mixture of iso-propanol:methanol (1:1) in a chromatotron to obtain pure flabelliferins. ${ }^{8}$

Assay of flabelliferins: This was conducted using a computerized densitometer by methods described previously. ${ }^{8}$

Administration of $10 \%$ PFP containing feed: PFP containing feed was prepared by substituting one-third the maize with 10\% PFP on dry basis (when PFP was used) in WHO standard rat and mouse breeding feed. Test and control diets were isocaloric. Mice (36) were divided into 6 groups ( 6 in each), 3 control groups and 3 test groups.

(I) One set (a control and a test group) was used for the weight gain study and at the end of 2 wks their fasting blood sugar levels were tested.

(II) In the $2^{\text {nd }}$ set, $10 \%$ PFP containing feed was given to the test group and the WHO standard rat and mouse breeding feed was given to the control group. Faeces were collected on the following day for testing of reducing substances.

(III) 'The remaining set of animals were given 10\% PFP containing feed (test) and WHO standard rat and mouse breeding feed (control) for a day. On the following day they were given a glucose load and after $1.5 \mathrm{~h}$ they were sacrificed to collect blood and intestinal samples.

Administration of flabelliferins: The dosage of mixed flabelliferins administered to the test group was $10 \mathrm{mg} /$ $50 \mathrm{~g}$ mouse in $0.5 \mathrm{~mL}$ distilled water (calculated on the basis of the yield of flabelliferins after separation from PFP and food intake of a mouse). Controls were given the same volume of water. The dosage of mixed flabelliferins without ultra violet (uv) binder administered was $2 \mathrm{mg} / 50 \mathrm{~g}$ mouse in $0.5 \mathrm{ml}$ distilled water.

The dosage of purified flabelliferins (calculated on the basis of preliminary experiment) was: F-II, $1 \mathrm{mg} / 50 \mathrm{~g}$ mouse, $\mathrm{FB}, 3 \mathrm{mg} / 50 \mathrm{~g}$ mouse, $\mathrm{FD}+\mathrm{FE}, 1.5 \mathrm{mg} / 50 \mathrm{~g}$ mouse.
Extractives were administered orally using a Sondi needle by the gastric garage method.

Glucose challenge: Mice were fasted overnight and glucose (Glaxo - Welcome Co.) dissolved in distilled water, was orally administered to mice at a dose of $1.5 \mathrm{~g} / \mathrm{kg}$ body weight in a volume of $0.5 \mathrm{~mL}$.

Collection and assay of faeces: Faeces were collected $24 \mathrm{~h}$ after administration of glucose and the total sugar content was determined by the Dinitrosalicylic acid (DNS) method.?

\section{Estimation of glucose in blood}

Fasting blood glucose: Animals were fasted for $12 \mathrm{~h}$ and they were sacrificed under diethyl ether anesthesia. Blood $(0.5 \mathrm{~mL})$ was drawn by cardiac puncture and the blood glucose concentrations analysed immediately using a reagent kit (DMA, USA) employing the glucose oxidase method. ${ }^{10}$

Post prandial blood glucose: Animals were sacrificed under diethyl ether anasthesia, $90 \mathrm{~min}$ post glucose loading $(2 \mathrm{~h}$ after administration of extract) and the glucose level was determined as before.

Collection of intestinal samples and determination of glucose content in the intestinal wash ": Animals were fasted overnight and the test group was orally administered the extractive $30 \mathrm{~min}$ prior to the glucose challenge. The control group was orally administered distilled water $(0.5 \mathrm{~mL} / 50 \mathrm{~g}$ mouse) at the same time. The animals in the test group and the control group were sacrificed $1.5 \mathrm{~h}$ after the administration of glucose load under diethyl ether anasthesia and their intestines removed. Intestines from each animal were washed with $25 \mathrm{~mL}$ of distilled water and the washings centrifuged at $3000 \mathrm{rpm}$ for 10 min. The supernatant was tested by the glucose oxidase method ${ }^{10}$ to determine the glucose content.

\section{Statistical analysis}

All the results are presented as (mean \pm S.E.) Statistical analysis was carried out in Microsoft Excel. The significance was tested by Student's t-test. A probability level of $p<0.05$ was chosen as the cut off point of statistical significance, but accurate $p$ values were calculated using the computer software.

\section{RESULTS}

1. Flabelliferin profile. 'Total flabelliferin content in the PFP sample used in the present study was $0.5 \% / \mathrm{PFP}$ 
$(50 \mathrm{mg} / 100 \mathrm{~g})$. The sample was a bulk sample from Kalpitiya, one of the main sources of PFP. The percentages of the pure flabelliferins (per total flabelliferins) were F-II - 51\%, FB - 3.9\%, FD + FE - $41.5 \%$ in this sample.

\section{Studies using $10 \%$ PFP.}

(i) Animal set 1 . Weanling ICR mice fed over a period of 2 weeks with 10\% PFP containing feed showed a marked decrease in weight gain $(p=0.007$, Table 1) compared to control mice fed with the PFP free diet, although food intake did not decrease significantly $(p=0.7)$. This had been previously reported ${ }^{5,6}$. No significant difference was found in the fasting blood sugar levels between the test and control animals $(p=0.64)$.

(ii) Animal set 2. The reducing sugar content in the faeces of the test group of animals was significantly higher $(p<0.0001)$ than in the control group, while the faecal fat content was similar ( $14.77 \%$ in test group and $14.47 \%$ in controls).

(iii) Animal set 3 . The test group of animals had significantly lower blood glucose levels $(p<0.001)$ with no significant changes in the intestinal glucose content $(p=0.21)$ after a glucose challenge (Table 1$)$.

\section{Studies using mixed flabelliferins.}

Animal set 1 . Test mice $(\mathrm{n}=6)$ were administered 10 $\mathrm{mg} / 50 \mathrm{~g}$ mouse mixed flabelliferins in $0.5 \mathrm{~mL}$ of water for 7 days. Controls were given the same volume of water. At the end of the 7 day period of feeding with the mixed flabelliferins, the test animals had a lower weight gain than $(p=0.01)$ the control animals. However, fasting blood sugar did not vary markedly $(p=0.11)$.

Animal set 2. There was no significant difference between faecal weight of test animals and controls. However, after a glucose challenge, faecal sugar $(p<0.01)$ and intestinal glucose $(p<0.001)$ in the test animals increased significantly while blood glucose showed a marked decline $(p<0.0001)$ when compared to the corresponding values in control animals (Table 2). Separating the fluorescent binder from mixed flabelliferins gave larger decline even when the dose was reduced to $2 \mathrm{mg} / 50 \mathrm{~g}$ mouse(Table 2).

\section{Separated flabelliferins.}

F-II. Oral administration of the flabelliferin F-II $(\mathrm{MW}=1030)$ containing uv binder $(\mathrm{MW}=544)$ after a glucose challenge resulted in a significant increase in intestinal glucose content $(p<0.001)$ and decrease in blood glucose level $(p<0.001)$ with no change in faecal sugar and faecal weight, despite the dose being only $1 \mathrm{mg} / 50 \mathrm{~g}$ mouse (Table 2).

$\mathrm{FB}$ and $\mathrm{FD}+\mathrm{FE}$. Administration of $\mathrm{FB}(3 \mathrm{mg} / 50 \mathrm{~g}$ mouse) and $\mathrm{FD}+\mathrm{FE}(1.5 \mathrm{mg} / 50 \mathrm{~g}$ mouse) resulted in a reduction in intestinal glucose content and elevation in blood glucose level after a glucose challenge. This was the reverse of the effect observed with F-II (Table 2).

Table 1: Effect of 10\% PFP containing feed on weight gain and blood and intestinal glucose after a glucose load $(1.5 \mathrm{~g} / \mathrm{Kg} \mathrm{BW})$

\begin{tabular}{lccc}
\hline & Control & Test & p value \\
\hline $\begin{array}{l}\text { A. Average weight } \\
\text { gain in 2 weeks }\end{array}$ & $12.2 \pm 0.56$ & $6.9 \pm 1.48$ & 0.007 \\
$\begin{array}{l}\text { B. Mean blood glucose } \\
\begin{array}{l}\text { level (mg/dL) } \\
\text { C. Mean glucose of intestinal }\end{array}\end{array}$ & $185.3 \pm 5.7$ & $162.9 \pm 3.5$ & 0.001 \\
wash & $9.7 \pm 1.6$ & $10.8 \pm 3.7$ & 0.21 \\
\hline
\end{tabular}

A: test animals $=6$, were given $10 \%$ PFP containing feed and the control group was given WHO standard rat and mouse breeding feed for two weeks.

$B$ and $C$ : after feeding for one day the mice were given a glucose load and after $1.5 \mathrm{~h}$ they were sacrificed to collect blood and intestinal samples.

Mean \pm S.E. 
Table 2: Effects of flabelliferins on glucose content in blood, faeces and intestinal wash after glucose challenge.

$\begin{array}{ccc}\begin{array}{c}\text { Mean blood glucose } \\ \mathrm{mg} / \mathrm{dI}\end{array} & \begin{array}{c}\text { Mean faecal sugar } \\ \text { content } \mathrm{mg} / \mathrm{dL}\end{array} & \begin{array}{c}\text { Mean glucose in } \\ \text { intestinal wash } \mathrm{mg} / \mathrm{dL}\end{array}\end{array}$

A. Mixed flabelliferins (10 $\mathrm{mg} / \mathrm{mouse})$ containing uv binder

$\begin{array}{lrrr}\text { Control } & 181.8 \pm 16.1 & 506 \pm 59.7 & 21.7 \pm 0.8 \\ \text { Test } & 102.9 \pm 7.9 & 720 \pm 28.1 & 126.3 \pm 3.0 \mathrm{P} \\ \text { P value } & <0.0001 & <0.01 & <0.001\end{array}$

B. Mixed flabelliferins ( $2 \mathrm{mg} /$ mouse) without uv binder

$\begin{array}{lrrr}\text { Control } & 297.5 \pm 4.3 & \text { Not tested } & 32.8 \pm 2.3 \\ \text { Test } & 178.6 \pm 5.1 & \text { Not tested } & 72.2 \pm 2.1 \\ \text { P value } & <0.001 & & <0.001\end{array}$

C. Separated flabelliferins (1mg F II, 3mg FB, 1.5mg FD + FE with uv binder/mouse respectively)

\begin{tabular}{lrrr} 
Control & $110 \pm 1.6$ & $967 \pm 6.2$ & $17.2 \pm 0.8$ \\
Test (F-II) & $62.6 \pm 3.6$ & $960 \pm 13.9$ & $345 \pm 1.1$ \\
P value & $<0.001$ & $=0.62$ & $<0.001$ \\
Control & $195.6 \pm 1.0$ & Not tested & $48.8 \pm 1.9$ \\
Test (FB) & $197.9 \pm 1.1$ & Not tested & $44.0 \pm 1.8$ \\
P value & $=0.14$ & & $=0.1$ \\
Test (FD+FE) & $190.3 \pm 2.7$ & Not tested & $40.9 \pm 2.6$ \\
P value & $=0.09$ & & $=0.07$ \\
\hline
\end{tabular}

Test and control mice $(n=6$ each) were fasted for $12 \mathrm{~h}$, and a glucose load $(1.5 \mathrm{~g} / \mathrm{Kg} \mathrm{BW})$ was given 30 min after administration of test flabelliferins. Glucose content in blood and intestinal wash was determined $2 \mathrm{~h}$ after extractive following sacrificing with diethyl ether anesthesia. Faeces were collected in a separate trial, $24 \mathrm{~h}$ after administation of F-II, and analysed for sugar in test and controls. A, B, and C were separate trials with their own controls. Chad two controls, one for F-II trial and another for the other flabelliferins.

Mean + SEM

\section{DISCUSSION}

The results confirm previous observations $s^{3,5}$ that administration of PFP containing feed results in a significant weight loss. The insignificant effect on fasting blood sugar of mice fed on $10 \%$ PFP could probably be attributed to the high sugar content (about $80 \%$ on a dry weight basis of PFP) which may serve to counteract the hypoglycaemic effects of the active principle. In addition, gluconeogenesis that would occur during fasting may also contribute to maintaining blood glucose homeostasis.

Experiments with separated flabelliferins, clearly showed that F-II (flabelliferin tetraglycoside) is the compound that inhibits absorption of glucose from the intestinal lumen and this results in a reduction of blood glucose on glucose challenge (an anti hyperglycaemic effect) and probably leads to the reduced weight gain observed previously ${ }^{3,5}$. It is interesting that faecal glucose content was not found to be significantly higher on administration of pure F-II. This could be attributed to absence of the antimicrobial flabelliferin (FB) ${ }^{4}$ in pure F.II. FB, that is present in mixed crude flabelliferins is known to inhibit a wide range of bacteria ${ }^{+}$, possibly inhibits bacteria of the large intestine and leads to high glucose in the faeces of mice administered with crude flabelliferins or fed with 10\% PFP containing feed. The effects of flabelliferins plus and minus the uv active binder on glucose challenge show that separation of the binder increases the efficiency with which the flabelliferins, probably flabelliferin F-II, reduces intestinal glucose uptake even when calculations are made on molar basis. It should be noted that the F-II constitutes $50 \%$ of the mixed flabelliferins while flabelliferins $F B, F D$ and $F E$ make up most of the rest. This study shows that FB, FD and $\mathrm{FE}$ produce no decline of glucose uptake.

The overall results have implications on the use of F-Il as either an anti-obesity or anti-diabetic food component. The fact that PFP is non-toxic to mice even at $50 \%$ incorporation in feed ${ }^{2}$ lends weight to this possible application.

\section{Acknowledgement}

The authors thank the National Science Foundation of Sri Lanka for the grant NSF/RG/M/01 and IPICS SRI: 07 for purchase of special chemicals. 


\section{References}

1. Jansz E.R., Nikawala J.K., Gunaratne M.J. \& Thievendirarajah K. (1994). The bitter principle and debittering of palmyrah fruit pulp. fournal of the Science of Food and Agriculture 65: 185-189.

2. Nikawala J.K., Jansz E.R., Abeysekera A.M., Wijeyarame S.C. \& Gamage U.C. (1998). Studies on chemistry and bioactivity of the flabelliferins, steroidal saponins from palmyrah (Borassusfabellifer) fruit pulp. Chemistry in Sri Lanka $15(1): 6-7$.

3. Ariyasena D.D. (2002). The Diversity, Bioactivity and Structural studies of flabeliferins from palmyrah (Borassus flubellifer L.) fruit pulp. M. Phil. Thesis. University of Sri Jayewardenepura, Sri Lankà.

4. Nikawala J.K., Wijeyaratne S.C., Jansz E.R. \& Abeysekera A.M. (1998). Flabelliferins, steroidal saponins from palmyrah fruit (Borassus flabellifer L.) pulp. II I'reliminary studies on effect on yeast and selected bacteria. Journal of the National Science Corncil of Sri Lanka 25: 141-150.

5. Ariyasena D.D., Jayasekera S., Jansz E.R. \& Abeysekera A.M (2000). Effect of palmyrah (Borassits flathellifer) fruit pulp on weight gain by mice. Vidyodaya Journal of Science 9: 99105.
6. Ariyasena D.D., Jansz E.R., Jayasekera S. \& A beysekera A.M., (2000). Inhibitory effect of bitter principle of palmyrah (Borassis flabellifer L.) fruit pulp on the growth of mice: Evidence using bitter and non bitter fruit pulp. Journal of the Science of Food and Agriculture 80: 1763-1766.

7. Sabourdy M. A. (1988). Breeding and care of laboratory animals. WHO/Lab 88: 1.1:45.

8. Nikawala J. K., Ariyasena D. D., Jansz E. R. \& Abeysekeara A. M. (2000). Separation techniques of flabelliferins from palmyrah (Borassus flabellifer) fruit pulp. Journal of Science, Eastern University of Sri Lanka 1: 1-9.

9. Miller G. L. (1959). Use of dinitrosalicylic acid reagent for determination of reducing sugars. Analytical Chemistry 31: 426-428.

10. Hugget A.St.G. \& Nixon D. A.(1957). Use of glucose peroxidase and dianisidine in the determination of blood and urinary glucose. Lancet $I I, 368-370$.

11. Fernando M. R. \& Thabrew M. I. (2001). Extra- pancreatic effects contributing to the hypoglycaemic activity of Artocarpus beterophyllus. The Coylon Journal of Medical Sciences 44: 1-10.

12. Uluwaduge I., Thabrew M.I. \& Jansz E.R. (2003). Short term and long term toxicity studies of palmyrah (Borassus flabellifer) fruit pulp. Proceedings of Sri Lanka Association for the Advancement of Science 59: 2. 